\title{
Effects of Fertilizer Application Rate and Planting Density on Photosynthetic Characteristics, Yield and Yield Components in Waxy Wheat
}

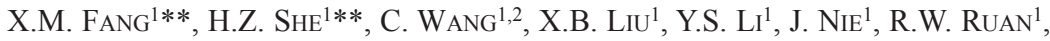 \\ T. WANG ${ }^{3}$ and Z.L. YI* \\ ${ }^{1}$ College of Agronomy and Biotechnology, Southwest University, Beibei, Chongqing 400716, China \\ ${ }^{2}$ Institute of Upland Food Crops, Guizhou Academy of Agricultural Sciences, \\ Guiyang, Guizhou 550006, China \\ ${ }^{3}$ Chengdu Institute of Biology, Chinese Academy of Sciences, Chengdu, Sichuan 610041, China \\ (Received 9 March 2017; Accepted 13 June 2017; \\ Communicated by J.H. Zhang)
}

Waxy wheat (Triticum aestivum L.) is grown throughout the world for its specific quality. Fertilization and planting density are two crucial factors that affect waxy wheat yield and photosynthetic capacity. The objectives of the research were to determine the effects of fertilization and planting density on photosynthetic characteristics, yield, and yield components of waxy wheat, including Yield, SSR, TGW, GNPP, GWPP, PH, HI, Pn, Gs, Ci, E and WUE using the method of field experiment, in which there were three levels $(150,300$, and $450 \mathrm{~kg}$ $\left.\mathrm{ha}^{-1}\right)$ of fertilizer application rate and three levels $\left(1.35,1.8\right.$, and $2.25 \times 10^{6}$ plants ha $\left.^{-1}\right)$ of planting density. The results suggested that photosynthetic characteristics, yield, and yield components had close relationship with fertilization levels and planting density. Under the same plant density, with the increase of fertilization, Yield, SSR, TGW, GNPP, GWPP, HI, $\mathrm{Pn}, \mathrm{Gs}, \mathrm{E}$ and WUE increased and then decreased, $\mathrm{PH}$ increased, but $\mathrm{Ci}$ decreased. Under the same fertilization, with the increase of plant density, Yield, SSR, TGW, GNPP, GWPP, $\mathrm{HI}$ increased and then decreased, $\mathrm{PH}, \mathrm{Pn}$, Gs and $\mathrm{E}$ increased, $\mathrm{PH}$ and WUE declined. The results also showed that F2 $\left(300 \mathrm{~kg} \mathrm{ha}^{-1}\right)$ and D2 $\left(1.8 \times 10^{6}\right.$ plants ha $\left.^{-1}\right)$ was a better match in this experiment, which could obtain a higher grain yield $4961.61 \mathrm{~kg} \mathrm{ha}^{-1}$. Consequently, this combination of fertilizer application rate and plant densities are useful to get high yield of waxy wheat.

Keywords: waxy wheat, fertilizer application rate, planting density, photosynthetic characteristics, yield, yield components

Abbreviations: SSR, seed setting rate; TGW, thousand-grain weight; GNPP, grain number per plant; GWPP, grain weight per plant; PH, plant height; HI, harvest index; Pn, net photosynthesis rate; Gs, stomatal conductance; $\mathrm{Ci}$, intercellular carbon dioxide concentration; E, transpiration rate; WUE, water use efficiency

\footnotetext{
*Corresponding author; E-mail: yzlin1969@126.com

** Equal contribution.
} 


\section{Introduction}

Waxy wheat (Triticum aestivum L.) has a promising production due to its specific quality and was extensively used in many fields, particularly in food processing industry. Because the waxy wheat does not contains amylase at all or it contains very lower level of amylase ( $\mathrm{Zi}$ et al. 2015). However, there is no complete waxy mutant in hexaploid wheat under the natural condition and it needs to be produced artificially. Fortunately, waxy wheat was first developed by Nakamura in Japan in 1995 (Chen 2000). Quality-character analysis and noodle-making experiments indicated that rheological properties were significantly different between waxy wheat and common wheat, and that common wheat flour mixing with some waxy wheat flour can greatly improve the taste quality of noodles (Li and Ning 2001). In addition, the difference between waxy wheat mochi and waxy rice mochi demonstrated that waxy wheat mochi was easier to chew and swallow (Fujita et al. 2012).

The addition of $\mathrm{N}$ fertilizer was an effective way to increase crop yield in dryland areas and an appropriate increase in planting density may be another approach to high yield (Gao et al. 2009). An experiment was carried out in different agro-ecological regions of China and it was found out that the wheat yield increases from fertilization were still significant (Wang et al. 2010). Fertilization treatments at different soil depths affected the net photosynthetic rate (Pn), transpiration rate (E) and stomatal conductance (Gs) of flag leaf and leaf area index (LAI) (Geng et al. 2006). Fertilizer amount and planting density influence wheat grain filling process. Moderate fertilization and high planting density are most favorable to wheat grain filling (Liu et al. 2009). Adding fertilizer application increased wheat population and biomass under different fertilizer application treatments in the condition of super-high-yielding wheat cultivation (Zhao et al. 2002).

Planting density could remarkably influence the radiation utilization of wheat and optimum planting density had apparent advantages in light distribution, coefficient and radiation use efficiency of total biological yield at late growth period. The effect of planting density on yield and yield components were all statistically significant (Bi et al. 2010). Also, the interactions of sowing date and planting density on spike number, grains per spike and grain yield were significant ( $\mathrm{Hu}$ et al. 2008). Previous studies showed that middle-density was moderate since the use of limited light, fertilizer, water and other resources was reasonable, the single plant grew better, the population yield was also higher (Hou et al. 2011). With sowing rates increasing, the daily Pn and E of flag leaf changed indistinctively, meanwhile the daily Pn and E of both backward 3rd leaf and backward 5th leaf declined markedly (Wu and Ou 2008).

Fertilization and planting density are two crucial factors that affect waxy wheat yield and photosynthetic capacity. Most of previous studies with fertilization and planting density have focused on the yield and yield components of wheat (Horvat et al. 2006; Liu et al. 2006; Bertic et al. 2007; Baloch et al. 2010; Kolb et al. 2012). However, little is known about fertilization and planting density on the yield and yield components of waxy wheat, especially on the photosynthetic characteristics of waxy wheat. The objective of this study was to investigate the effects of fertilization and planting density on the photosyn- 
thetic characteristics, yield and yield components in waxy wheat. A great understanding of that information would help characterize the photosynthetic mechanism for changed grain yield under fertilization and planting density in modern waxy wheat production systems.

\section{Materials and Methods}

\section{Site description}

The field experiments were conducted during October 2013 to June 2014 and October 2014 to June 2015 at the Rice Research Institute of Southwest University, Chongqing, China. The area is classified as subtropical monsoon climate. The monthly mean rainfall, temperature and monthly sunshine duration during waxy wheat growing seasons from 2013-2015 are shown in Fig. S1*. And the soil at the site is classified as a loamy clay soil, and the 0 to $100 \mathrm{~mm}$ soil layer contained $1.26 \%$ organic matter, $0.08 \%$ total $\mathrm{N}, 0.05 \%$ total $\mathrm{P}$, and $1.75 \%$ total $\mathrm{K}$. The $\mathrm{pH}$ value of the soil was 5.8 .

\section{Experimental design}

The experiment was a split-plot factorial, on the basis of randomized complete block design with five replications. The main plots had fertilizer rate with three levels: 150 (F1), 300 (F2), and 450 (F3) $\mathrm{kg} \mathrm{ha}^{-1}$. The subplots had the planting density with three levels: 1.35 (D1), 1.8 (D2), and 2.25 (D3) $\times 10^{6}$ plants ha ${ }^{-1}$. The area of the individual plots was $10 \mathrm{~m}^{2}(2 \mathrm{~m} \times 5 \mathrm{~m})$. Each plot had six rows, and there were three guard rows around the area.

In this study, we used waxy wheat Zhongkenuomai No. 1 from Chengdu Institute of Biology, Chinese Academy of Sciences, which was authorized the first waxy wheat variety in Chongqing, and planted widely around Chongqing. High concentration $\mathrm{K}_{2} \mathrm{SO}_{4}$ compound fertilizer applied $\left(\mathrm{N} 15 \%, \mathrm{P}_{2} \mathrm{O}_{5} 15 \%, \mathrm{~K}_{2} \mathrm{O} 15 \%\right)$ as basal applications.

\section{Indicators and measuring method}

The photosynthetic characteristics of the leaves from five uniform plants were measured at the flowering stage with $L I-6400 X T$ portable photosynthetic apparatus (LI-COR, USA). An intact, disease-free flag leaf was selected and its net photosynthetic rate (Pn), stomatal conductance (Gs), intercellular carbon dioxide concentration $(\mathrm{Ci})$ and transpiration rate (E) were measured from 09:30 to 11:00. These measurements were used to calculate WUE $(\mathrm{Pn} / \mathrm{E})$. The measurements were taken at the atmospheric $\mathrm{CO}_{2}$ concentration of 360 to $400 \mu \mathrm{mol} \mathrm{m} \mathrm{m}^{-2} \mathrm{~s}^{-1}$ and the flow rate of $400 \mathrm{~mL} \mathrm{~min}^{-1}$. The instrument was equipped with an artificial light source. We measured photosynthesis characteristics as soon as possible to minimize the influence of temperature.

*Further details about the Electronic Supplementary Material (ESM) can be found at the end of the article. 
The crops were harvested at maturity at a ground level, and their aboveground biomass and grain yield were measured after drying to a constant mass. The yield and biomass were calculated from the central four rows of each plot. HI was calculated as (grain yield)/ (aboveground biomass). The SSR, TGW, GNPP, GWPP and PH were recorded for ten uniform plants.

\section{Statistical analysis}

The differences in data across the two years were not significant $(\mathrm{P}>0.05)$. Therefore, for all indicators, mean data of the two years were presented. Analysis of variance (one-way ANOVA) was performed with SPSS 19.0 software (SPSS Institute Inc., Chicago, USA), and data from each sampling data were analyzed separately. Means were tested by least significant difference at the $\mathrm{P}<0.05$ level $\left(\mathrm{LSD}_{0.05}\right)$.

\section{Results}

\section{Yield}

Results of variance analysis (Table S1) showed that, the effects of fertilization, planting density and their interaction on the yield were significant at 0.01 and 0.05 probability levels, respectively. Grain yield increased to its maximum at F2 and subsequently decreased at F3 (Table 1). The statistics suggested there were significant differences between the yield of F1, F2 and F3. Similarly, the grain yield increased to its peak value at D2, which was higher than D3. Furthermore, there were significant differences between the yield of D1, D2 and D3. With fertilization F2, waxy wheat yield tended to be in the range of 3865.70 to $4961.61 \mathrm{~kg} \mathrm{ha}^{-1}$ as per different planting density, as follows: D2 $>$ D3 $>$ D1. Interaction between fertilization and planting density on the grain yield (Table 2) showed that F2D2 was the best.

\section{Yield components}

SSR: Fertilization, planting density and their interaction had significant effects on the SSR in waxy wheat (Table S1). There were significant differences in SSR among fertilization treatments, and the maximum value appeared in the F2 (Table 1). Compared with the F1 and F3, F2 significantly increased the SSR. In addition, there were significant differences in SSR among planting density. The SSR increased and then decreased with the increase of planting density and the maximum value appeared in the D2. Compared with the D1 and D3, D2 significantly increased the SSR. Interaction between fertilization and planting density (Table 2) showed that the F2D2 had the highest SSR.

TGW: The effects of fertilization, planting density and their interaction on the TGW were significantly observed (Table S1). There were significant differences in TGW among fertilization treatments, and TGW changed from increasing to decreasing of waxy wheat (Table 1). TGW reached the peak $40.18 \mathrm{~g}$ in F2. There were significant differences in 

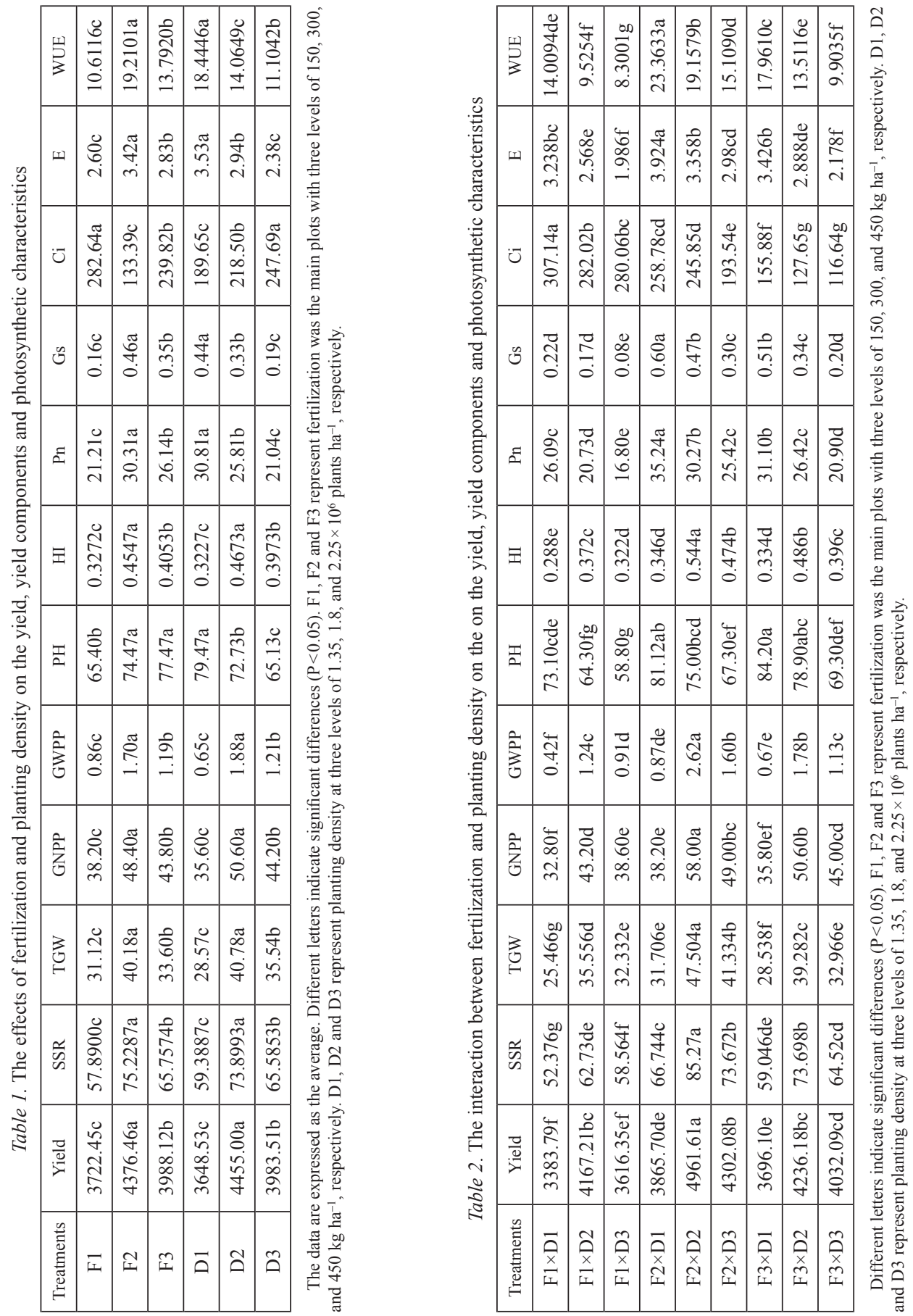

Cereal Research Communications 46, 2018 
TGW among planting density treatments. With different planting density, TGW increased and then decreased as planting density increased. Interaction between fertilization and planting density (Table 2) showed that the F2D2 obtained the highest TGW.

GNPP: As shown in Table S1, the effects of fertilization and planting density on the GNPP were significantly observed. There were significant differences in GNPP among fertilization treatments (Table 1). When fertilization ranged from F1 to F3, the GNPP was increased and then decreased with the increase of fertilization. There were significant differences in GNPP among planting density treatments. With different planting density, GNPP increased and then decreased as planting density increased. The interaction between fertilization and planting density had no significant effect on the GNPP. However, the results (Table 2) showed that the F2D2 had the highest GNPP.

GWPP: It can be concluded that fertilization, planting density and their interaction had significant effects on the GWPP in waxy wheat (Table S1). As for fertilization treatments, there were significant differences in GWPP among fertilization treatments (Table 1). GWPP in the F2 treatment was greater than in the other fertilization rate treatments. Likewise, there were significant differences in GWPP among planting density treatments. When planting density was increased from D1 to D2, GWPP increased about threefold, from $0.65 \mathrm{~g}$ to $1.88 \mathrm{~g}$. When planting density was increased from D2 to D3, GWPP decreased to $1.21 \mathrm{~g}$. Interaction between fertilization and planting density (Table 2) showed that the F2D2 obtained the highest GWPP.

PH: According to the analysis of variance (Table S1), fertilization and planting density had significant effects on the $\mathrm{PH}$ in waxy wheat. While, the interaction between fertilization and planting density on the PH was none significant. There were significant differences between F2, F3 and F1 but the difference between F2 and F3 was not significant (Table 1). Under the same planting density treatments, PH increased with the increase of fertilization. The maximum value $77.47 \mathrm{~cm}$ was observed at F3. There were significant differences in $\mathrm{PH}$ among planting density treatments. Especially, $\mathrm{PH}$ decreased from $79.47 \mathrm{~cm}$ to $65.13 \mathrm{~cm}$ with the increase of planting density.

HI: According to the analysis of variance (Table S1), fertilization, planting density and their interaction had significant effects on the HI in waxy wheat. There were significant differences in GWPP among fertilization treatments (Table 1). In addition, there were significant differences in GWPP among planting density treatments. Similar to the change trend of GWPP, HI exhibited single peak curve with the highest HI at F2 and D2. Interaction between fertilization and planting density (Table 2) showed that the F2D2 obtained the highest HI.

\section{Photosynthetic characteristics}

Pn: Results of analysis of variance (Table S1) showed that fertilization and planting density had significant effects on the Pn in waxy wheat. The effect of the interaction between fertilization and planting density on Pn was not significant. In terms of fertilization treatments, there were significant differences among fertilization treatments (Table 1). And when fertilization increased to F2, Pn arrived at $30.31 \mu \mathrm{mol} \mathrm{m} \mathrm{m}^{-2} \mathrm{~s}^{-1}$. Fertilization in- 
creased from F2 to F3, Pn decreased by $13.8 \%$. In terms of planting density treatments, there were significant differences among planting density treatments. Pn trended to decrease with the increase of planting density and the maximum value of Pn was observed at D3. Interaction between fertilization and planting density (Table 2) showed that the F2D1 had the highest Pn $35.24 \mu \mathrm{mol} \mathrm{m}{ }^{-2} \mathrm{~s}^{-1}$.

Gs: In the case of Gs, fertilization, planting density and their interaction had significant effects on the Gs in waxy wheat (Table S1). There were significant differences in Gs among fertilization treatments. Similarly, there were significant differences in Gs among planting density treatments (Table 1). Compared with the F1 and F3, F2 significantly increased the Gs. In addition, the Gs increased and then decreased with the increase of planting density and the maximum value appeared in the D2. Compared with the D1 and D3, D2 significantly increased the Gs. Interaction between fertilization and planting density (Table 2) showed that the F2D1 had the highest Gs $0.60 \mathrm{mmol} \mathrm{m}^{-2} \mathrm{~s}^{-1}$.

$\mathrm{Ci}$ : As shown in Table S1, the effects of fertilization and planting density on the $\mathrm{Ci}$ were significantly observed but their interaction had non-significant effect on the $\mathrm{Ci}$. There were significant differences in $\mathrm{Ci}$ among fertilization treatments (Table 1). Ci extremely decreased from $282.64 \mu \mathrm{mol} \mathrm{mol}^{-1}$ to $133.39 \mu \mathrm{mol} \mathrm{mol}{ }^{-1}$ along with the increase of fertilization from F1 to F2. When fertilization grew from F2 to F3, Ci was increased from $133.39 \mu \mathrm{mol} \mathrm{mol}^{-1}$ to $239.82 \mu \mathrm{mol} \mathrm{mol}^{-1}$. There were significant differences in $\mathrm{Ci}$ among planting density treatments and $\mathrm{Ci}$ increased and then decreased with the increase of planting density. The maximum value appeared in the D3. Compared with D1, the D3 significantly increased the $\mathrm{Ci}$ by $30.6 \%$. Interaction between fertilization and planting density (Table 2) showed that the F1D1 had the highest Ci.

E: According to the analysis of variance (Table S1), fertilization and planting density had significant effects on the PH in waxy wheat. While the effect of the interaction between fertilization and planting density on the PH was insignificant. There were significant differences in $\mathrm{Ci}$ among fertilization treatments and the maximum value appeared in the F2 (Table 1). Compared with F1 and F3, the F2 increased E by 31.5\%, 20.8\%, respectively. There were significant differences in $\mathrm{E}$ among planting density treatments and $\mathrm{E}$ was decreased with the increase of planting density. Compared with D1, the D3 was decreased by $32.6 \%$. Interaction between fertilization and planting density (Table 2 ) showed that the F2D1 had the highest E $3.924 \mathrm{~m}^{-2} \mathrm{~s}^{-1} \mathrm{a}^{-1}$.

WUE: In terms of WUE, fertilization, planting density and their interaction had significant effects on the WUE in waxy wheat (Table S1). There were significant differences in WUE among fertilization treatments and the highest value observed in the F2 (Table 1). Compared with F1 and F3, the F2 was extremely increased by $81 \%$ and $39.3 \%$, respectively. There were significant differences in WUE among planting density treatments and WUE decreased with the increase of planting density. Compared with D1, the D3 was decreased by $39.8 \%$. Interaction between fertilization and planting density (Table 2) showed that the F2D1 had the highest WUE. 


\section{Correlation analysis between yield and all of the examined characteristics}

It can be concluded that the Pn, Gs, Ci, E, WUE and PH were all had no significant effects on the yield; while remarkable positive correlations were found between the grain yield of waxy wheat and SSR, TGW, GNPP, GWPP and HI (Table S2).

\section{Discussion}

Both fertilizer application rate and plant density have significant effects on crop yield. Nakano and Morita (2009) reported that there was little significant interaction between fertilization levels and planting density on grain yield. In general, it was widely believed that more fertilizer and particularly more planting density could lead to high yield. However, high planting density lead to low efficiency of light capture and small spikes, as well as small grains, which have consequently produced low yield. As mentioned in previous studies, crop yield usually revealed a curvilinear response to plant density or fertilizer rates, and it reached a maximum level at the optimum plant density or fertilizer application rate (Ciampitti and Vyn 2011; Ma et al. 2014; Zhang et al. 2014a, b; Roques and Berry 2016).

Our results indicated that middle level of fertilization in F2 $\left(300 \mathrm{~kg} \mathrm{ha}^{-1}\right)$ would increase grain yield and yield components of waxy wheat, compared with the lowest level of fertilization F1 (150 kg ha ${ }^{-1}$ ) and the highest level of fertilization F3 (450 kg ha $\left.{ }^{-1}\right)$. But the lowest level of fertilization F1 (150 $\left.\mathrm{kg} \mathrm{ha}^{-1}\right)$ improved photosynthetic capacity. Previous studies for fertilization effect on grain yield of waxy wheat were in agreement with ours (Liu et al. 2006; Qu et al. 2009; Zhang et al. 2016).

Planting density also shows a marked influence on wheat quality traits and should be considered a particularly important factor contributing to grain yield. This study showed that middle planting density in D2 $\left(1.8 \times 10^{6}\right.$ plantings ha $\left.^{-1}\right)$ would increase grain yield and grain yield related factors. And the lowest planting density D1 $\left(1.35 \times 10^{6}\right.$ plantings ha $\left.{ }^{-1}\right)$ increased the photosynthetic production. However, the result was not in complete agreement with Gooding et al. (2002), who reported that grain yield decreased with an increase of planting density from 200 to 600 seeds $\mathrm{m}^{-2}$ (approximately $1 \times 10^{6}$ plants $^{-1}$ to $2.28 \times 10^{6}$ plants $\mathrm{ha}^{-1}$ ) under different levels of $\mathrm{N}$ fertilization because of a marked decline in the kernels per spike. This difference may be attributable to differences in genotype characteristics.

In the present study, there were significant correlations between yield and yield component (SSR, TGW, GNPP, GWPP and HI), except for PH. However, the yield and yield component had no significant relations with $\mathrm{Pn}$ and $\mathrm{Pn}$ related variables (Pn, Gs, Ci, E and WUE). Previous studies shown that leaf photosynthetic rate is poorly correlated with yield when different genotypes of crop species are compared; even negative relations between photosynthesis and grain yield have been reported (Evans 1993, 1998; Reynolds et al. 2000; Richards 2000). Genetic changes related to increased rates of leaf photosynthesis have not been accompanied by yield increases in major crops, suggesting that leaf photosynthesis does not limit plant growth and yield and/or that the crops may have ad- 
equate photosynthetic capacity. This result would lead to the viewpoint that improvement of leaf photosynthesis is not a useful strategy to increase crop yield (Richards 2000; Sinclair et al. 2004; Zhao et al. 2008). In spite of PH not significantly affected grain yield, Chen and Hao (2015) showed that the semidwarf wheat shows a strong adaption to dry environment and it contributes to the significant increase in wheat yields. Yamori et al. (2016) showed that enhancing photosynthesis at the single-leaf level would be a useful target for improving crop productivity and yield both via conventional and molecular breeding.

In conclusion, fertilization, planting density and their interaction had significantly effects on the photosynthetic characteristics, yield and yield components of waxy wheat. The field study demonstrated that certain dose of fertilization and reasonable planting density can be used successfully to increase the yield, seed setting rate (SSR), thousandgrain weight (TGW), grain number per plant (GNPP), grain weight per plant (GWPP), net photosynthesis rate (Pn), stomatal donductance (Gs), transpiration rate (E) and water use efficiency (WUE) and declined plant height (PH) and intercellular carbon dioxide concentration (Ci). Furthermore, the optimal combination was fertilizer application rate 300 $\mathrm{kg} \mathrm{ha}^{-1}$ and planting density $1.8 \times 10^{6}$ plants ha ${ }^{-1}$.

\section{Acknowledgements}

This research was supported by the Sino-Dutch Topic Research Partnership (JSTP, 2013 DEG 31380), Ministry of Science and Technology of China. And the key project of Chongqing Application and Development Plan (cstc 2013 yykfB 80012).

\section{References}

Baloch, M.S., Shah, I.T.H., Nadim, M.A., Khan, M.I., Khakwani, A.A. 2010. Effect of seeding density and planting times on growth and yield attributes of wheat. Japs J. of Animal and Plant Sci. 20:239-242.

Bertic, B., Loncaric, Z., Vukadinovic, V., Vukobratovic, Z., Vukadinovic, V. 2007. Winter wheat yield responses to mineral fertilization. Cereal Res. Commun. 35:245-248.

Bi, C.R., Bai, Z.Y., Yang, S., Li, C.D., Zheng, J.F., Li, D.X., Tang, G.L. 2010. Effects of planting density on radiation resource utilization of the wheat colony. Acta Agriculturae Boreali-Sinica 5:171-176.

Chen, X., Hao, M.D. 2015. Low contribution of photosynthesis and water-use efficiency to improvement of grain yield in Chinese wheat. Photosynthetica 4:519-526.

Chen, X.M. 2000. The research progress on waxy wheat. Acta Triticale Crops 2:82-85.

Ciampitti, I.A., Vyn, T.J. 2011. A comprehensive study of plant density consequences on nitrogen uptake dynamics of maize plants from vegetative to reproductive stages. Field Crops Res. 121:2-18.

Evans, L.T. 1993. Crop Evolution, Adaptation and Yield. CUP. Cambridge, MA, USA.

Evans, L.T. 1998. Greater crop production: whence and whither? In: Waterlow, J.C., Armstrong, D.G., Fowden, L., Riley, R. (eds), Feeding a World Population of More Than Eight Billion People - A Challenge to Science. Oxford University Press. Cary, NC, USA. pp. 89-97.

Fujita, S., Kumagai, T., Yanagimachi, M., Sakuraba, S., Sanpei, R., Yamoto, M., Tohara, H. 2012. Waxy wheat as a functional food for human consumption. J. Cereal Sci.. 55:361-365.

Gao, Y., Li, Y., Zhang, J.C., Liu, W.G., Dang, Z.P., Cao, W.X., Qiang, Q. 2009. Effects of mulch, N fertilizer, and plant density on wheat yield, wheat nitrogen uptake, and residual soil nitrate in a dryland area of China. Nutrient Cycling in Agroecosystems 85:109-121. 
Geng, W., Xue, X., Wang, Z.M. 2006. Effects of deep fertilization on photosynthetic characteristics and yield of winter wheat. Acta Triticale Crops 26:166-168.

Gooding, M.J., Pinyosinwat, A., Ellis, R.H. 2002. Responses of wheat grain yield and quality to seed rate. J. Agric. Sci. 138:317-331.

Horvat, D., Loncaric, Z., Vukadinovic, V., Drezner, G., Bertic, B., Dvojković, K. 2006. The influence of mineral fertilization on winter wheat yield and quality. Cereal Res. Commun. 34:429-432.

Hou, H.Z., Lv, J.F., Guo, T.W. 2011. Planting density in soil over film-mulched and bunch-seeded wheat. Crops 3:101-104.

Hu, H.H., Li, L.P., Li, R.Q., Li, H.L., Li, Y.M. 2008. Effect of sowing date and planting density on the yield formation of a winter wheat cultivar Henong 822. Acta Triticale Crops 3:490-495.

Kolb, L.N., Gallandt, E.R., Mallory, E.B. 2012. Impact of spring wheat planting density, row spacing, and mechanical weed control on yield, grain protein, and economic return in Maine. Weed Sci. 60:244-253.

Li, Z.A., Ning, K. 2001. Primary report on waxy wheat studies. Acta Triticale Crops 21:95-96.

Liu, J.H., Niu, J.Y., Yan, Z.L. 2009. Physiological characteristics of grain filling in high quality winter wheat under different fertilizer application dose and plant density. Chinese J. of Eco-Agriculture. 17:890-894.

Liu, P., Guo, W.S., Xu, Y.M., Feng, C.N., Zhu, X.K., Peng, Y.X. 2006. Effect of planting density on grain yield and quality of weak - gluten and medium - gluten wheat. Acta Triticale Crops 5:117-121.

Ma, N., Yuan, J., Li, M., Li, J., Zhang, L.Y., Liu, L.X., Naeem, M.S., Zhang, C.L. 2014. Ideotype population exploration: Growth, photosynthesis, and yield components at different planting density in winter oilseed rape (Brassica napus L.). PloS one 9:e114232.

Nakano, H., Morita, S. 2009. Effects of seeding rate and nitrogen application rate on grain yield and protein content of the bread wheat (Triticum aestivum) cultivar 'Minaminokaori' in southwestern Japan. Plant Production Sci. 12:109-115.

Qu, H.J., Li, J.C., Shen, X.S., Wei, F.Z., Wang, C.Y., Zhi, S.J. 2009. Effects of plant density and seeding date on accumulation and translocation of dry matter and nitrogen in winter wheat cultivar Lankao Aizao 8. Acta Agron. Sin. 35:124-131.

Reynolds, M.P., Ginkel, M.V. 2000. Avenues for genetic modification of radiation use efficiency in wheat. J. Exp. Bot. 343:459-473.

Richards, R.A. 2000. Selectable traits to increase crop photosynthesis and yield of grain crops. J. Exp. Bot. 343:447-458.

Roques, S.E., Berry, P.M. 2016. The yield response of oilseed rape to plant population density. J. Agr. Sci. 154:305-320.

Sinclair, T.R., Purcell, L.C., Sneller, C.H. 2004. Crop transformation and the challenge to increase yield potential. Trends in Plant Sci. 9:70-75.

Wang, X., Li, Z.Y., Ma, W.Q., Zhang, F.S. 2010. Effects of fertilization on yield increase of wheat in different agro-ecological regions of China. Scientia Agricultura Sinica 43:2469-2476.

Wu, L.F., Ou, Y.Z. 2008. Photosynthesis of two spike-type cultivars of winter wheat (Triticum aestivum L.) under different sowing rates. Acta Agron. Sin. 28:618-625.

Yamori, W., Kondo, E., Sugiura, D., Terashima, I., Suzuki, Y., Makino, A. 2016. Enhanced leaf photosynthesis as a target to increase grain yield: Insights from transgenic rice lines with variable Rieske FeS protein content in the cytochrome b6/f complex. Plant Cell Environ. 39:80-87.

Zhang, D.S., Zhang, L.Z., Liu, J.G., Han, S., Wang, Q., Evers, J., Liu, J., van der Werf, W., Li, L. 2014a. Plant density affects light interception and yield in cotton grown as companion crop in young jujube plantations. Field Crops Res. 169:132-139.

Zhang, Y., Dai, X.L., Jia, D.Y., Li, H.Y., Wang, Y.C., Li, C.X., Xu, H.C., He, M.R. 2016. Effects of plant density on grain yield, protein size distribution, and bread making quality of winter wheat grown under two nitrogen fertilisation rates. Eur. J. Agron. 73:1-10.

Zhang, Y., Ding, G.D., Cai, H.M., Xu, F.S., Shi, L. 2014b. Effects of different planting methods on root system architechture and yield of oilseed rape. J. Huazhong Agric. Univ. 33:25-32.

Zhao, G.C., Liu, L.H., Yang, Y.S., Zhang, Y., Yang, Z.S. 2002. Effect of fertilizer application on population quality, root system distribution, grain yield and quality in super-high-yielding wheat. Acta Agriculturae Boreall-Sinica 17:82-87. 
Zhao, X.Q., Xu, J.L., Zhao, M., Lafitte, R., Zhu, L., Fu, B.Y., Gao, Y.M. 2008. QTLs affecting morpho-physiological traits related to drought tolerance detected in overlapping introgression lines of rice (Oryza sativa L.). Plant Sci. 174:618-625.

Zi, Y., Ding, J.F., Huang, Z.J., Wang, L.A., Ju, F., Zhai, C.Y., Jiang, W., Zhu, X.K., Li, C.Y., Guo, W.S. 2015. Population quality indexes for waxy wheat Yangnuomai 1 with yield higher than $8000 \mathrm{~kg} \mathrm{ha}^{-1}$. Acta Agron. Sin. 5:797-805.

\section{Electronic Supplementary Material (ESM)}

Electronic Supplementary Material (ESM) associated with this article can be found at the website of CRC at http://www.akademiai.com/content/120427/

Electronic Supplementary Table S1. Variance analysis the effects of fertilization and planting densities on the yield, yield components and photosynthetic characteristics

Electronic Supplementary Table S2. Correlation analysis between yield and all the examined characteristics

Electronic Supplementary Figure S1. The monthly mean temperature, rainfall and monthly sunshine duration during waxy wheat growing seasons from 2013-2015 at Chongqing, China 